\title{
Robotic lateral heller myotomy without fundoplication for achalasia
}

\author{
Farid Gharagozloo, Nabiha Atituzzman, Basher Atiquzzman \\ Center for Advanced Thoracic Surgery, Global Robotics Institute, Advent Health Celebration University of Central Florida, \\ Celebration, FL 34786, USA.
}

Correspondence to: Dr. Farid Gharagozloo, Center for Advanced Thoracic Surgery, Global Robotics Institute, Advent Health Celebration University of Central Florida, 400 Celebration Place, Celebration, FL 34786, USA. E-mail: gharagozloof@aol.com

How to cite this article: Gharagozloo F, Atituzzman N, Atiquzzman B. Robotic lateral heller myotomy without fundoplication for achalasia. Mini-invasive Surg 2020;4:22. http://dx.doi.org/10.20517/2574-1225.2019.61

Received: 17 Dec 2019 First Decision: 6 Feb 2020 Revised: 6 Mar 2020 Accepted: 13 Mar 2020 Published: 10 Apr 2020

Science Editor: Noriyoshi Sawabata Copy Editor: Jing-Wen Zhang Production Editor: Tian Zhang

\begin{abstract}
Aim: Laparoscopic anterior esophageal myotomy with a Dor anterior fundoplication is the most commonly performed surgical myotomy procedure. A lateral esophageal myotomy without an antireflux procedure performed through a left thoracotomy has been associated with the lowest rate of postoperative gastroesophageal reflux and the highest rate for relief of dysphagia. The surgical robot allows for the lateral myotomy procedure to be performed by laparoscopy rather than thoracotomy. We studied our experience with Robotic Lateral Heller Myotomy Without Fundoplication (RLHM) for achalasia.
\end{abstract}

Methods: A retrospective review was conducted of the patients with achalasia who underwent RLHM. All patients completed a subjective dysphagia score questionnaire, received an Eckardt Score, and underwent manometry and pH testing preoperatively, as well as at 6 and 12 months following the myotomy procedure.

Results: Forty-eight patients underwent RLHM. The median operating room time was 85 min (range 60-132 min). There was no conversion to a laparotomy. Median hospitalization was 2 days (range 2-3 days). There were no mucosal perforations, complications, or deaths. Following RLHM, the Lower Esophageal pressure decreased from $35 \mathrm{mmHg}$ (range $18-120 \mathrm{mmHg}$ ) to $13.2 \mathrm{mmHg}$ (range $9.8-16.6 \mathrm{mmHg})(P<0.0001)$. The length of the Lower Esophageal high-pressure xone decreased from $5.5 \mathrm{~cm}$ (range $4-9 \mathrm{~cm})$ to $2.2 \mathrm{~cm}$ (range $1.5-2.8 \mathrm{~cm})(P<0.0001)$. Two patients $(2 / 48)(4.2 \%)$ had pathologic gastroesophageal reflux. The median acid exposure in all patients was $0.4 \%$ (range $0 \%-17.8 \%$ ), and the median Demeester score was 7.5 (range 2-125). The Eckardt score decreased from $6.3 \pm 1.8$ to $0.8 \pm 1.8$ at 1 month ( $P<$ $0.0001)$, and $0.8 \pm 1.1$ at 12 months $(P<0.0001)$.

Conclusion: RLHM is associated with excellent relief of dysphagia and a low incidence of new gastroesophageal reflux.

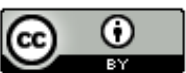

(C) The Author(s) 2020. Open Access This article is licensed under a Creative Commons Attribution 4.0 International License (https://creativecommons.org/licenses/by/4.0/), which permits unrestricted use, sharing, adaptation, distribution and reproduction in any medium or format, for any purpose, even commercially, as long as you give appropriate credit to the original author(s) and the source, provide a link to the Creative Commons license, and indicate if changes were made.

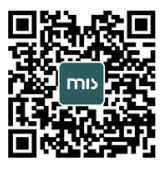


Keywords: Achalasia, robotic, heller myotomy, laparoscopic, eckhardt score

\section{INTRODUCTION}

Achalasia is characterized by abnormal relaxation of the lower esophageal muscle and absence of progressive peristalsis in the body of the esophagus ${ }^{[1]}$. In patients with achalasia, histopathologic studies of the lower esophagus have shown depletion of the ganglion cells and inflammation of the myenteric plexus $^{[2-3]}$. Since the function of the lower esophageal myenteric plexus cannot be restored, presently, the treatment of achalasia is palliative. The therapeutic options include medical therapy, botulinum toxin injections, pneumatic dilation, and distal esophageal myotomy by laparoscopy or endoscopy.

Although laparoscopic anterior esophageal myotomy with a Dor anterior fundoplication is the most commonly performed surgical myotomy procedure, several controversies persist, including the ideal operative approach, anterior vs. lateral esophageal myotomy, the extent of esophageal myotomy, and the need for the addition of an antireflux procedure.

Ellis et al. ${ }^{[4]}$ reported that, after a lateral esophageal myotomy without an antireflux procedure performed through a left thoracotomy, there was $96 \%$ relief of dysphagia and 3.5\% rate of post myotomy gastroesophageal reflux. An anterior myotomy is thought to divide the gastroesophageal valve at its midpoint, necessitating an antireflux procedure. However, by performing the myotomy laterally and preserving the antireflux barrier, a fundoplication may be unnecessary. On the other hand, a lateral myotomy by thoracoscopy has been associated with high rates of post-myotomy reflux ${ }^{[5]}$. These results have been attributed to the shortcomings of conventional videoendoscopic visualization and instruments. By virtue of high definition magnified $3 \mathrm{D}$ visualization and precise instrument maneuverability in a small space, it has been reasoned that a surgical robot can enable the lateral myotomy procedure to be performed by laparoscopy. We studied our experience with robotic laparoscopic lateral Heller myotomy without an antireflux procedure for achalasia (RLHM).

\section{METHODS}

A retrospective review was conducted of the patients with achalasia who underwent RLHM. Diagnosis of achalasia was made by esophagogram, endoscopy, and manometry. Patients who had previously undergone a myotomy or had a hiatal hernia were excluded from this study. Patients who had undergone a previous myotomy underwent redo myotomy by left thoracotomy, and patients with a hiatal hernia underwent an anterior myotomy with repair of the hiatal hernia and Dor fundoplication. All patients completed a subjective dysphagia score questionnaire, received an Eckardt score, and underwent manometry and $\mathrm{pH}$ testing preoperatively. The dysphagia score, manometry, and $\mathrm{pH}$ testing were repeated at 6 months following the myotomy procedure. The validated dysphagia score instrument scores subjective severity and frequency of dysphagia on a scale from 0 to 5 with a total possible Score of 0-10 for each individual ${ }^{[6]}$. The dysphagia score is presented as median and range. The Eckardt achalasia scoring instrument scores dysphagia, regurgitation, retrosternal pain, and weight loss from 0 to 3 with a total possible score of 0-12 for each individual ${ }^{[7]}$. In addition, the Eckardt score was tabulated at 1 and 12 months after RLHM. The Eckhardt score is presented as mean \pm SE. Failure of myotomy was defined as an Eckhardt score of $\geq 3$.

The study was reviewed and determined to be exempt from institutional review board approval under 45 CFR 46.101 (b).

\section{Surgical technique}

The procedure is performed on a laparoscopic platform [Figure 1]. Preoperative upper gastrointestinal endoscopy is performed and the gastroesophageal junction is examined by the retroflexed endoscope. 


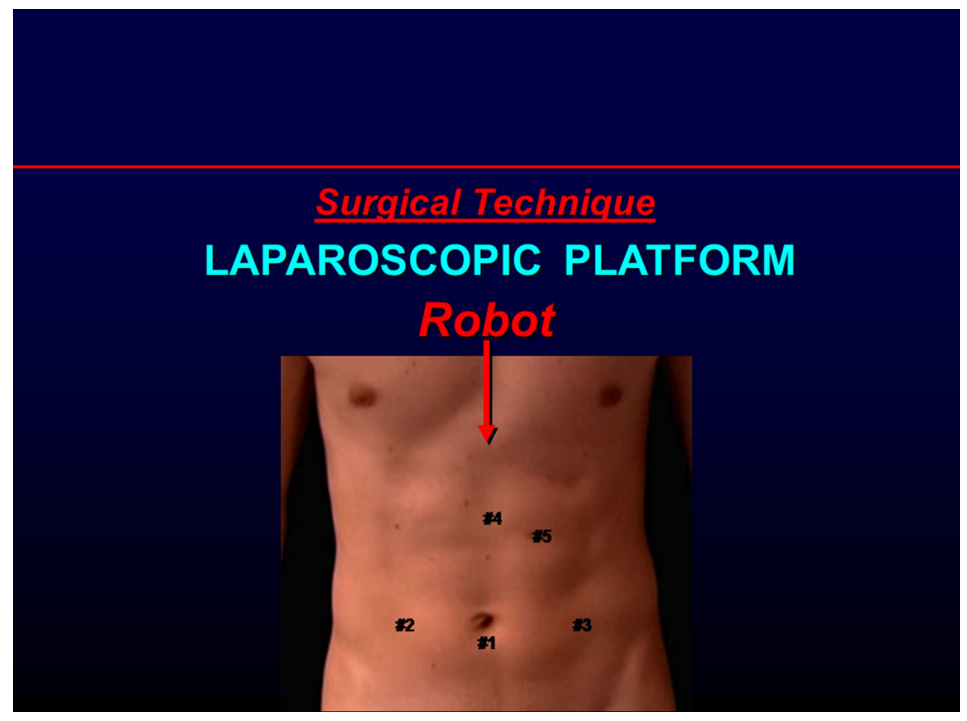

Figure 1. Positioning the robot and trocars for the robotic approach

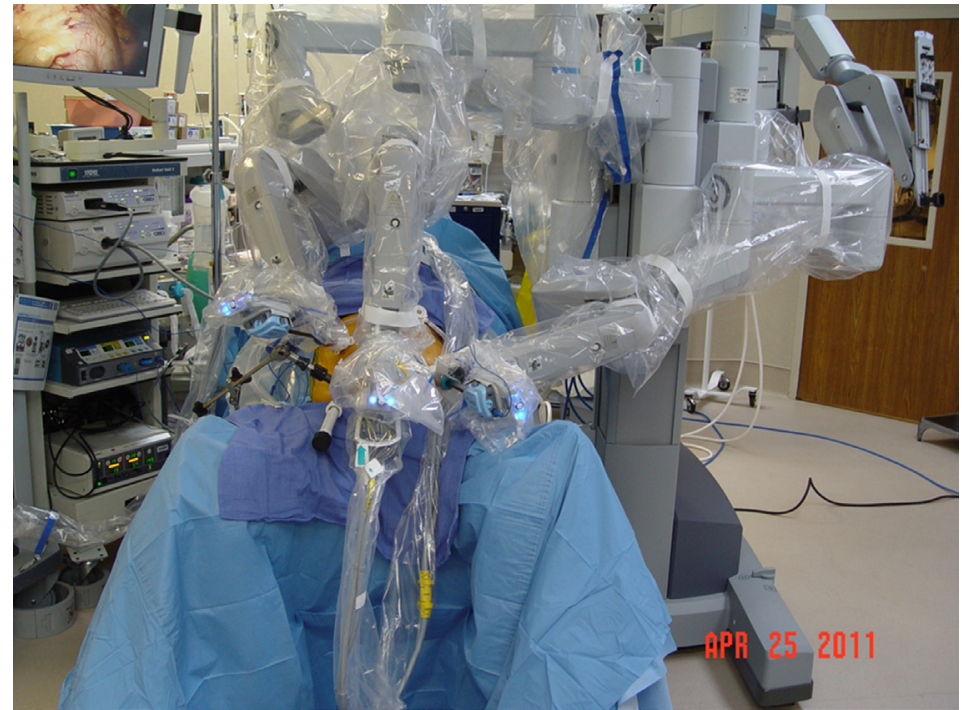

Figure 2. Positioning the robot for the robotic laparoscopic approach

Two Laparoscopic $\mathrm{CO}_{2}$ insufflators are used. Port 1 (Camera Port) is placed inferior to the umbilicus. Pneumoperitoneum is created. The table is placed in a steep reverse Trendelenberg position. Port 2 is placed in the right paraumbilical region at the right mammary line. Port 3 is placed in the left paraumbilical region in the left mammary line. An Endo-Paddle paddle retractor (Medtronic, Norwalk, Conn.) is introduced through Port 2 and used to place upward traction on the left lobe of the liver. Port 4 is placed in the subcostal region halfway between the umbilicus and the xiphoid just to the left of the midline. This port is aligned with the right limb of the right crus of the diaphragm. Port 5 is placed in the subcostal region two finger-breaths to the left and caudad to Port 4 . Port 5 is aligned with the left limb of the right crus of the diaphragm.

The surgical robot (Da Vinci Si, Intuitive Surgical, Sunnyvale, CA) is docked using the "side docking" technique [Figure 2]. A 30-degree down-viewing robotic binocular camera is used, which is introduced through Port 1 . The right robotic arm with a hook cautery instrument is introduced through Port 3. The 


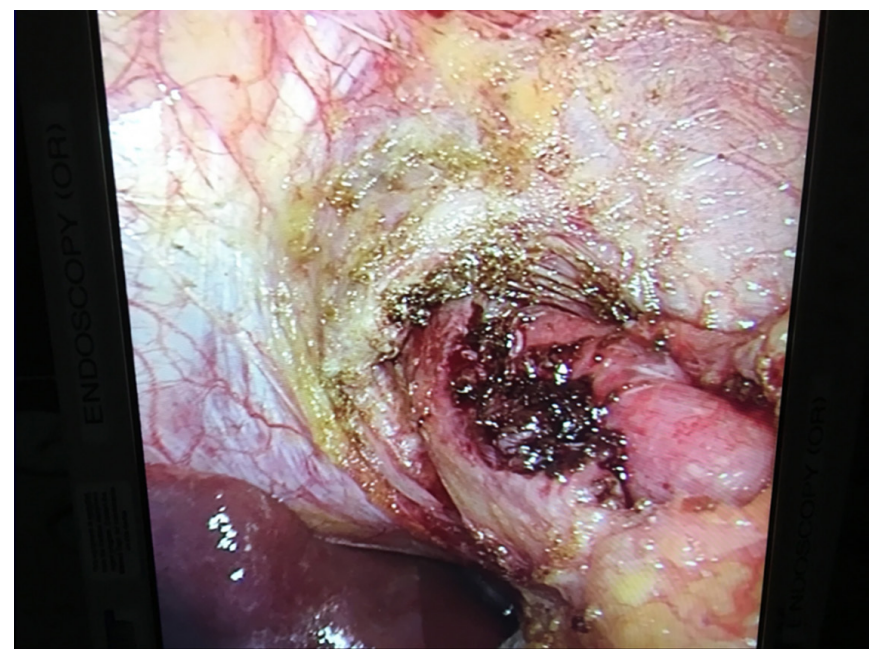

Figure 3. Laparoscopic view of the completed lateral esophageal myotomy prior to the re-approximation of the left limb of the esophageal crus

left robotic arm with a Debakey grasper instrument is introduced through Port 2. The entire dissection uses electrocautery and meticulous hemostasis. An Endo-Paddle Retract Retractor (Covidian, Norwalk, Conn, USA) is introduced through Port 5 by the assistant and is used to provide appropriate counter traction and exposure at the esophagogastric junction.

The left limb of the esophageal crus is identified, and the muscle is divided perpendicular to the direction of the fibers for half the width of the crus. Care is taken not to enter the pleura, which resides just under the crus. The left limb is not transected completely. This allows for partial retraction of the muscle away from the lateral aspect of the gastroesophageal junction while at the same time facilitating repair of the left limb at the end of the procedure. The hook cautery is set at $30 \mathrm{cut} / 30$ coagulation with blend setting. The stomach is retracted inferiorly, thereby straightening the gastroesophageal (GE) junction. Care is taken to stay on the left lateral aspect of the gastroesophageal valve. Theoretically, by preserving the gastroesophageal valve and the phreno-esophageal ligament, the antireflux mechanism is kept intact. The muscle of the esophagus is divided to the level of the mucosa. The hook cautery them completes the myotomy approximately $2 \mathrm{~cm}$ onto the cardia of the stomach. Myotomy is discontinued when the submucosal vascular plexus of the stomach wall is visualized [Figure 3]. The myotomy is extended cephalad on the esophagus to the level of the pleura. The total length of the myotomy is approximately $6 \mathrm{~cm}$.

At this point, an assistant who is positioned at the head of the patient advances the gastroscope past the GE junction into the stomach. The ease of movement of the gastroscope into the stomach and the lack of resistance further confirms the complete division of the esophageal muscles at the GE junction. Furthermore, the gastroscope is retroflexed to view the GE junction from a caudad to cephalad direction [Figure 4]. Observation of the trans-illuminated mucosa of the proximal portion of the gastric cardia from the light of the robotic camera serves as the final confirmation for the completion of the esophageal myotomy. The retroflexed view further confirms that the myotomy is lateral to the gastroesophageal valve. Following the completion of the myotomy, the area is filled with saline and the gastroscope is used to insufflate air into the stomach and esophagus in order to rule out any mucosal perforation.

Following a satisfactory myotomy, the partially transected left limb of the esophageal crus is reapproximated with two O-Ethibond sutures (Ethicon, Inc. Sommerville, NJ) with $2-\mathrm{cm}$ square absorbable pledgets cut from Vicryl mesh (Ethicon, Inc. Sommerville, NJ).

A video of the procedure can be accessed at https://www.youtube.com/watch? $\mathrm{v}=$ WUEuHSioodY \&feature $=$ youtu.be. 


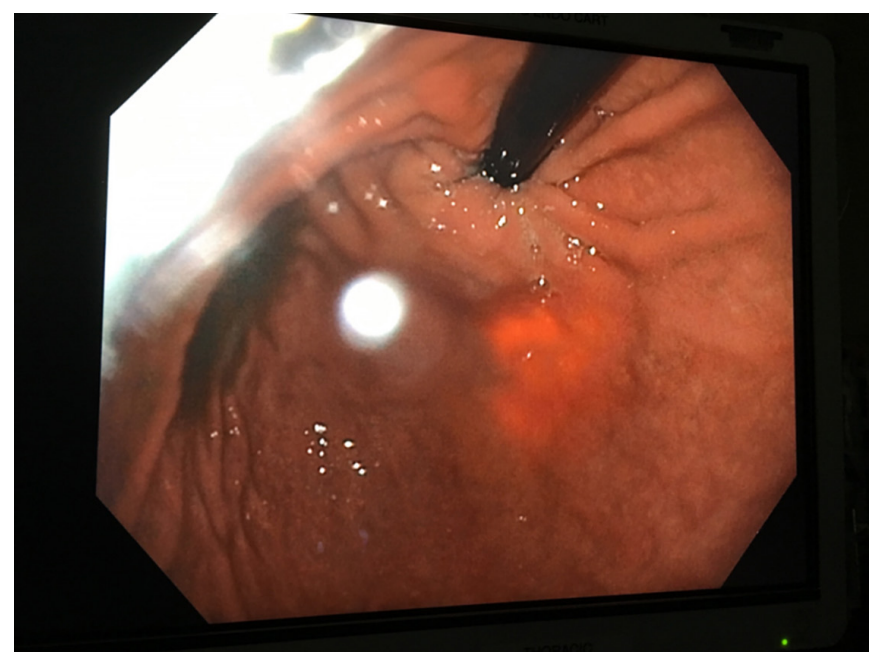

Figure 4. Retroflexed endoscopic view of the intact gastroesophageal valve and trans-illuminated lateral esophageal myotomy

\section{RESULTS}

Forty-eight patients underwent RLHM. There were 25 men and 23 women with a mean age of $48 \pm 21$ years. Median OR time was $85 \mathrm{~min}$ (range 60-132 $\mathrm{min}$ ). There was no conversion to a laparotomy.

Median hospitalization was 2 days (range 2-3 days). There were no mucosal perforations, complications, or deaths. Manometry data are shown in Table 1.

Following RLHM, the Lower esophageal (LES) Pressure decreased from $35 \mathrm{mmHg}$ (range 18-120 $\mathrm{mmHg}$ ) to $13.2 \mathrm{mmHg}$ (range 9.8-16.6 $\mathrm{mmHg})(P<0.0001)$. The length of the LES high-pressure zone decreased from $5.5 \mathrm{~cm}$ (range $4-9 \mathrm{~cm}$ ) to $2.2 \mathrm{~cm}$ (range $1.5-2.8 \mathrm{~cm})(P<0.0001)$ [Table 2].

Following RLHM, based on the DeMeester score, two patients (4.2\%) had pathologic gastroesophageal reflux. Median acid exposure in all patients was $0.4 \%$ (range 0\%-17.8\%), and the median Demeester score was 7.5 (range 2-125).

Following RLHM, the dysphagia score decreased from 9 (range 8-10) to 1 (range 0-1) $(P=0.01)$ [Table 3].

Eckardt scores are shown in Table 4. Following RLHM, the Eckardt score decreased from $6.3 \pm 1.8$ to 0.8 $\pm 1.8(P<0.0001)$ at 1 month and $0.8 \pm 1.1$ at 12 months $(P<0.0001)$. Postoperatively, all patients had an Eckhardt score of less than 3.

\section{DISCUSSION}

The surgical therapy of achalasia has evolved with a better understanding of the disease process, the anatomy of the GE junction, and the nature of the "antireflux barrier", as well as advances in technology.

Over the years, surgical therapy for achalasia has been controversial. The controversy has centered on the ideal operative approach, the extent of esophageal myotomy, and the need for the addition of an antireflux procedure. With minor changes, presently, the same controversies continue.

A better understanding of the antireflux barrier has been crucial in understanding the reasons for the controversies. The antireflux barrier, which corresponds to the high-pressure zone on esophageal manometry, seems to be the result of the following: 
Table 1. Comparison of preoperative and postoperative LES high-pressure zone pressure (6 months)

\begin{tabular}{|c|c|c|}
\hline Postoperative LES & n (range) & \\
\hline Preop & Postop & $P$ value \\
\hline $35 \mathrm{mmHg}(18-120)$ & $13.2 \mathrm{mmHg}(9.8-16.6)$ & $<0.0001$ \\
\hline
\end{tabular}

LES: lower esophageal

Table 2. Comparison of preoperative and postoperative LES high-pressure zone length ( 6 months)

\begin{tabular}{lcl}
\hline \multicolumn{2}{l}{ Length of LES high-pressure zone median (range) } \\
\hline Preop & Postop & $\boldsymbol{P}$ value \\
\hline $5.5 \mathrm{~cm}(4-9)$ & $2.2 \mathrm{~cm}(1.5-2.8)$ & $<0.0001$ \\
\hline
\end{tabular}

LES: lower esophageal

Table 3. Comparison of preoperative and postoperative dysphagia score (6 months)

\begin{tabular}{lll}
\hline Dysphagia score median (range) & & \\
\hline Preop & Postop & P value \\
\hline $9(8-10)$ & $1(0-1)$ & $<0.01$ \\
\hline
\end{tabular}

Table 4. Comparison of preoperative and postoperative (12 months) Eckhardt score

\begin{tabular}{lll}
\hline Eckhardt score mean \pm SE & \\
\hline Preop & Postop & $\boldsymbol{P}$ value \\
\hline $6.3 \pm 1.8$ & $0.8 \pm 1.8$ & $<0.0001$ \\
\hline
\end{tabular}

(1) The anterior and lateral intussusception of the esophagus into the stomach, extending 270 degrees from the right limb of the right crus to the left limb of the right crus of the diaphragm.

(2) The crural sling exerts pressure in an anterior to posterior direction onto the GE junction and creates a slight angulation. This angulation at the GE junction serves to hold the intussuscepted esophagus in place and provides a slight resistance to reflux at the GE junction.

(3) The entire "antireflux" mechanism is held in place by the phreno-esophageal ligament and the tissues at the esophageal hiatus.

(4) Disruption of the esophageal hiatus, either with a hiatal hernia or at the time of surgical dissection, leads to the straightening of the GE junction, reduction of the anterior esophageal intussusception, and the creation of gastroesophageal reflux.

Prior to the advent of the laparoscopic approach to achalasia, the most commonly performed procedure for this disease was the transthoracic modified Heller myotomy with or without an antireflux procedure. The transthoracic approach was preferred to the transabdominal approach due to the technical difficulties of exposing the gastroesophageal junction and the distal esophagus by an open abdominal procedure. Ellis et al ${ }^{[4]}$ advocated transthoracic esophageal myotomy without an antireflux procedure with very low rates of postoperative reflux ${ }^{[8,9]}$. The advent of laparoscopy obviated the morbidity of a thoracotomy, and laparoscopic Heller myotomy with an anterior Dor fundoplication became one of the more frequently adopted surgical techniques for treating esophageal achalasia ${ }^{[10-18]}$.

In 1991, Shimi et al. ${ }^{[19]}$ reported the first laparoscopic experience for Heller myotomy. In one series of 133 patients who had undergone laparoscopic myotomy with a partial fundoplication, Patti et al. ${ }^{[20]}$ reported $11 \%$ persistent dysphagia, $17 \%$ new gastroesophageal reflux, and $5 \%$ mucosal perforations that were amenable to laparoscopic closure. Invariably, all series reporting the laparoscopic approach to Heller myotomy have shown excellent relief of dysphagia. The majority of difficulties with the laparoscopic approach have been related to reflux and the technical aspects of the fundoplication. In a series of 69 
patients undergoing laparoscopic myotomy and fundoplication for achalasia, Finley et al. ${ }^{[18]}$ reported a median operative time of $1.9 \mathrm{~h}$, one mucosal perforation that was amenable to laparoscopic repair, 96\% patient satisfaction for relief of dysphagia, and a $9 \%$ rate of new postoperative gastroesophageal reflux.

A generous anterior myotomy including onto the gastric cardia has been advocated to prevent incomplete myotomy presenting as residual achalasia. To prevent postoperative reflux, a fundoplication should be performed as well. The fundoplication has also been demonstrated to prevent the formation of a mucosal diverticulum following myotomy, a condition which may have added to the problem of chronic dysphagia in these patients with compromised esophageal dysmotility ${ }^{[18]}$.

On the other hand, the surgeons who have advocated myotomy without an antireflux procedure, most notably Ellis et al. ${ }^{[4]}$, have emphasized that, in their experience, fundoplication recreates the resistance to esophageal emptying and that, depending on the degree of resistance, fundoplication can lead to progressive esophageal dilation and ultimately the same sequalae as with untreated achalasia. Furthermore, based on performing a lateral esophageal myotomy, these authors have asserted that, in their experience, if the esophageal myotomy is carried onto the cardia by up to $2 \mathrm{~cm}$, an antireflux procedure is not required.

The present understanding of the gastroesophageal antireflux barrier has served to explain the different observations and the discrepancy in the experience of the proponents versus the opponents of an added antireflux procedure to the modified Heller myotomy. Based on this understanding, by nature of not disrupting the three-dimensional relationship at the esophageal hiatus and performing a very careful and limited myotomy, the surgeons who did not add an antireflux procedure were able to preserve the antireflux barrier and accomplish the goal of the myotomy without the need for an antireflux procedure. On the other hand, surgeons who opened the esophageal hiatus and performed an extensive dissection of the gastroesophageal junction, thus disrupting the normal antireflux barrier, needed to add an antireflux procedure to the myotomy in order to prevent postoperative reflux. It is important to note that, to visualize an adequate length of esophagus, a transabdominal approach invariably needs to disrupt the anatomy at the gastroesophageal junction and the antireflux barrier. Consequently, all transabdominal approaches to esophageal myotomy have required the addition of an antireflux procedure.

This is a retrospective review of patients who underwent a robotic laparoscopic esophageal myotomy without fundoplication. RLHM was performed without complications or mortality. There was significant decrease in the pressure and length of the lower esophageal high-pressure zone on manometry. The manometry data correlated with the significant decrease in the subjective dysphagia score. In addition, the objective Eckhardt scores decreased significantly and remained unchanged at 12 months following RLHM, signifying the long-term efficacy of the procedure. The rate of pathologic reflux following RLHM was very low. This finding is further evidence that RLHM preserves the gastroesophageal valve and does not require a fundoplication.

Long-term results of the laparoscopic anterior esophageal myotomy with an antireflux are excellent. Theoretically, by virtue of three-dimensional high definition magnification, and precise instrument maneuverability, the robotic laparoscopic approach may be associated with better outcomes for a procedure that requires exceptional surgical precision and visualization. In addition, the use of the surgical robot in performing a lateral esophageal myotomy may obviate the need for a fundoplication.

Given the excellent relief of dysphagia, and very low incidence of post myotomy gastroesophageal reflux, RLHM should be considered in patients with achalasia. 


\section{Study limitations}

The following limitations of this study should be considered before drawing definitive conclusions. The study was limited to a small number of patients. In addition, the study was retrospective and represented a highly selected group of patients.

Undoubtedly, the use of robotic technology adds greater cost. If the results of this study are validated by a randomized prospective study, this shortcoming may be offset by the greater accuracy of dissection, the high rates of relief of dysphagia, and the low incidence of pathologic reflux associated with robotic lateral Heller myotomy without fundoplication for achalasia.

\section{DECLARATIONS}

\section{Authors' contributions}

Collection of data, planning and preparation of manuscript: Gharagozloo F, Atituzzman N, Atiquzzman B

\section{Availability of data and materials}

Not applicable.

\section{Financial support and sponsorship}

None.

\section{Conflicts of interest}

All authors declared that there are no conflicts of interest.

\section{Ethical approval and consent to participate}

Not applicable.

\section{Consent for publication}

Not applicable.

\section{Copyright}

(c) The Author(s) 2020.

\section{REFERENCES}

1. Wood MG, Hagen JA. Primary esophgeal motor disorders. In: Pearson FG, editor. Esophageal surgery. 2nd. Elsevier Science; 2002. pp. 515-35.

2. Csendes A, Smok G, Braghetto I, Ramirez C, Velasco N, et al. Gastroesophageal sphincter pressure and histological changes in distal esophagus in patients with achalasia of the esophagus. Dig Dis Sci 1985;30:941-5.

3. Goldblum JR, Rice TW, Richter JE. Histopathologic features in esophagomyotomy specimens from patients with achalasia. Gastroenterology 1996;111:648-54.

4. Ellis FH Jr, Crozier RE, Watkins E. The operation foe esophageal achalasia: results of esophagomyotomy without an antireflux operation. J Thorac Cardiovasc Surg 1984;88:344-51.

5. Patti MG, Arcerito M, De Pinto M, Feo CV, Tong J, et al. Comparison of thoracoscopic and laparoscopic Heller myotomy for achalasia. J Gastrointest Surg 1998;2:561-6.

6. Youssef Y, Richards WO, Sharp K, Holzman M, Sekhar N, et al. Relief of dysphagia after laparoscopic Heller myotomy improves longterm quality of life. J Gastrointest Surg 2007;11:309-13.

7. Fisichella PM, Jalilvand A, Lebenthal A. Diagnostic evaluation of achalasia: from the whalebone to the Chicago classification. World J Surg 2015;39:1593-7.

8. Marwedel G. Die aufklappung des rippenbogens zur erleichterung operativer eingriffe in hypochondrum und im zwerchfellkuppelraum. Zentralbl Chir 1903;30:938.

9. Okike N, Payne SW, Neufeld DM. Esophagomyotomy versus forceful dilation for achalasia of the esophagus: results in 899 patients. Ann Thorac Surg 1079;28:119-25.

10. Donahue PE, Samelson S, Schlesinger PK, Bombeck CT, Nyhus LM. Achalasia of the esophagus. Treatment controversies and the method of choice. Ann Surg 1986;203:505-11.

11. Campos GM, Vittinghoff E, Rabl C, Takata M, Gadenstätter M, et al. Endoscopic and surgical treatments for achalasia: a systematic 
review and meta-analysis. Ann Surg 2009;249:45-57.

12. Mattioli S, Ruffato A, Lugaresi M, Pilotti V, Aramini B, et al. Long-term results of the Heller-Dor operation with intraoperative manometry for the treatment of esophageal achalasia. J Thorac Cardiovasc Surg 2010;140:962-9.

13. Malthaner RA, Todd TR, Miller L. Long term results in surgically managed esophageal achalasia. Ann Thorac Surg 1994;58:1343-7.

14. Topart P, Deschamps C, Taillefer R, Duranceau A. Long-term effect of total fundoplication on the myotomized esophagus. Ann Thorac Surg 1992;54:1046-51.

15. Shimi S, Nathanson LK, Cushieri A. Laparoscopic cardiomyotomy for Achalasia. J R Coll Surg Edinb 1991;36:152-4.

16. Patti MG, Pellegrini CA, Horgan S, Arcerito M, Omelanczuk P, et al. Minimally invasive surgery for achalasia: an 8-year experience with 168 patients. Ann Surg 1999;230:587-93.

17. Patti MG, Pellegrini CA, Arcerito M, Tong J, Mulvihill SJ, et al. Comparison of medical and minimally invasive surgical therapy for primary esophageal motility disorders. Arch Surg 1995;130:609-15.

18. Finley RJ, Clifton JC, Stewart KC, et al. Laparoscopic Heller myotomy for achalasia: a clinical and scintigraphic swallowing follow-up. Can J Surg 1999;42:25.

19. Shimi S, Nathanson LK, Cushieri A. Laparoscopic cardiomyotomy for Achalasia. J R Coll Surg Edinb 1991;36:152-4.

20. Patti MG, Pellegrini CA, Horgan S, Arcerito M, Omelanczuk P, et al. Minimally invasive surgery for achalasia: an 8-year experience with 168 patients. Ann Surg 1999;230:587-93. 